\title{
A single-center, prospective, observational study on maternal smoking during pregnancy in Greece: The HELENA study
}

\author{
George Skalis', Stefanos Archontakis', Costas Thomopoulos', Iliana Andrianopoulou', Ourania Papazachou', Georgia
} Vamvakou', Konstantinos Aznaouridis², Vasiliki Katsi², Thomas Makris'

\section{ABSTRACT}

INTRODUCTION The unequivocal association between exposure to smoke and numerous complications of pregnancy, demonstrated in the last decades, has led to a significant decrease of smoking rates in pregnancy. The aim of the present study was to determine the prevalence of maternal smoking and to elucidate factors predisposing to it among pregnant women in Athens, Greece.

METHODS A population of 1700 pregnant women (mean age: $31.2 \pm 5.5$ years) who visited consecutively the Cardiology Department of Helena Venizelou Maternity Hospital in Athens, Greece, between September 2016 and August 2017, was prospectively analyzed. Data regarding changes in the future mother's smoking habit as well as different sociodemographic factors potentially related to these changes were recorded.

RESULTS Of the 1700 participants, 704 (41.4\%) were smokers, and of those $52.4 \%$ quit smoking after knowledge of their pregnancy status. The overall prevalence of smoking in pregnancy was $19.7 \%$. Prevalence was higher in women who were aged $<20$ years $(p=0.038)$, were multipara $(p=0.032)$, had $\leq 12$ years of education $(p=0.044)$ and had a partner who was a smoker $(p=0.047)$. Women aged $\leq 20$ years were more likely to be persistent smokers at the beginning of pregnancy and demonstrated a higher prevalence of smoking during pregnancy $(42.2 \% \mathrm{vs}$ $19.7 \%$ in the overall study population).

CONCLUSIONS Our data demonstrate that maternal smoking during pregnancy still remains a major public health issue in Greece with a prevalence higher than most other industrialized countries.

\section{AFFILIATION}

1 Department of Cardiology, Helena Venizelou General \&t Maternity Hospital, Athens, Greece 2 First Cardiology Department, Hippokration General Hospital, University of Athens, Athens, Greece

CORRESPONDENCE TO

Stefanos Archontakis. Department of Cardiology, Helena Venizelou General \& Maternity Hospital, 1 Helenas Venizelou square, Athens, Greece. E-mail: stef6arch@yahoo. com

KEYWORDS

maternal smoking in pregnancy, smoking, pregnancy, smoking cessation, pregnancy complications

Received: 2 August 2020

Revised: 28 November 2020

Accepted: 19 December 2020

\section{INTRODUCTION}

Although smoking has been recognized as the most preventable cause of death worldwide ${ }^{1}$ and its prevalence in many countries has recently declined ${ }^{2}$, it still constitutes a major public health threat. In Europe the proportion of daily smokers in 2014 was $18.4 \%$ of the general population (aged $\geq 15$ years), ranging from $8.7 \%$ in Sweden to $27.0 \%$ in Greece and $27.3 \%$ in Bulgaria ${ }^{2}$. Among women, the proportion was $15.1 \%$, ranging from $8.3 \%$ in Romania to $21.3 \%$ in Greece and $22.0 \%$ in Austria ${ }^{2}$.
Numerous studies have demonstrated that prenatal smoking or exposure to smoke during pregnancy is associated with an increased risk of small-for-gestational-age infants and preterm delivery ${ }^{3-6}$, stillbirth ${ }^{4,7}$, complications such as placental abruption and premature rupture of membranes ${ }^{4}$, Sudden Infant Death Syndrome ${ }^{8,9}$ as well as several congenital malformations ${ }^{10,11}$. In addition, maternal smoking has been shown to be one of the most avoidable causes related to future health problems of childhood such as onset 
of childhood asthma ${ }^{12}$, neurological disorders ${ }^{13}$, childhood overweight and obesity ${ }^{14}$ and increased total mortality in future adult life $\mathrm{e}^{15}$. Finally, it is speculated that it may be related to behavioral problems and cognitive delays ${ }^{6,16,17}$.

Despite the well-established negative effects of tobacco on the fetus and child, the prevalence of smoking during pregnancy, albeit declining, still remains high ${ }^{18-25}$. In Greece, the total number of births was 88553 in $2017^{26}$. In two different studies published in 2010 and 2016, the prevalence of maternal smoking during pregnancy was reported at $17 \%$ and $26.3 \%$, respectively ${ }^{27,28}$. Several factors, such as marital status, parity, educational level, living with relatives who smoked, the smoking status of partner, the frequency of smoking and alcohol abuse have been identified to be associated with cessation of smoking during pregnancy ${ }^{27-30}$.

However, smoking in pregnancy is a dynamic social phenomenon, with a prevalence changing overtime. The present study aims to determine the prevalence of smoking among pregnant women visiting the largest maternity hospital in the city of Athens, Greece, and to investigate the risk factors affecting maternal smoking during pregnancy in this population. Recording updated data with regard to the present status of this major public health problem and providing a potential feedback for healthcare authorities designing antismoking policies is warranted.

\section{METHODS}

\section{Study design and population}

This is a single-center, prospective, observational cohort study conducted at the Cardiology Department of a large maternity health center in Athens, Greece, between September 2016 and August 2017. The study was conducted in the cardiology department since maternal smoking in pregnancy represents a major risk factor for cardiovascular mortality and morbidity, and due to the fact that all women about to give birth in our hospital should, by the hospital's protocol, have at least one regular cardiology assessment. In all, 1744 pregnant women visited consecutively the outpatient Cardiology Department during that period and 1700 were recruited in the study. In addition to the relatively large size of the population sample, women with various educational, social and economic levels were admitted in the study. Therefore, our population may be considered as representative with regard to the smoking status of pregnant women in Greece. All participants were residents of Athens. Participants were recruited if gestational age was $\geq 28$ weeks, however, 64 women $(3.8 \%)$ who had a gestational age of $\leq 27$ weeks were also included in our analysis. Women who agreed to participate in the study, after giving oral informed consent, were provided with a questionnaire by the nurses, midwives or doctors of our department. All procedures performed in the study were in accordance with the ethical standards of the institutional research committee and with the 1964 Helsinki Declaration and its later amendments, and have been approved by the local Ethics Committee of our Hospital. Participants provided oral informed consent prior to enrolment in the study. In addition, they were informed by the nurses and midwives of our team about the negative consequences of smoking in pregnancy both verbally and by smoking cessation leaflets. All personal data stored in electronic and hard-copy forms were pseudonymized.

Collected data included maternal age, week of pregnancy, parity, smoking habits before and during pregnancy, absolute number of cigarettes/ day both before and during pregnancy, level of education in the case that the future mother was a smoker, presence of dyslipidemia, chronic arterial hypertension and diabetes mellitus, presence of arterial hypertension and diabetes mellitus of pregnancy, and smoking status of the partner.

The prevalence of smoking in pregnancy was determined and different sociodemographic factors associated with cessation of smoking during pregnancy were identified.

\section{Definitions}

In the present study, women were classified either as non-smokers or smokers (defined as those who smoked $\geq 1$ cigarettes/day at the time they become aware of the pregnancy). The latter were further classified as active smokers if they continued to smoke during pregnancy, even occasionally, and quitters if they had completely stopped smoking. Furthermore, women who had previous pregnancies that reached a viable gestational age (including live births and stillbirths) were defined as multipara whereas women who did not have such pregnancies previously were classified as primipara. Moreover, high educational level was considered when 
women had university or other higher than 12 years of school education. In this study, educational level was recorded only for smokers. In the case that a partner was present, the smoking status was classified as smoker if at least 1 cigarette/day was consumed or non-smoker if the partner was not smoking or had completely quit smoking after becoming aware of the woman's pregnancy. Women who were single were excluded from partners' smoking status calculations. In the case that the pregnant woman was an active smoker, we also obtained the absolute number of the cigarettes/day both before and during pregnancy in order to identify whether the burden of smoking was: not reduced (i.e. no change in the number of cigarettes/day), mildly reduced $(<50 \%)$, moderately reduced $(51-80 \%)$ or significantly reduced $(>81 \%)$.

\section{Statistical analysis}

Continuous variables are expressed as mean \pm standard deviation, while categorical variables are presented as absolute or relative frequencies. For continuous variables, the assumption of normality was tested using the Kolmogorov-Smirnov criterion and with visual inspection of the distribution histograms. Comparisons of continuous variables (age) between smokers and non-smokers was performed using Student's t-test for unpaired measures. Pearson's chi-squared test was used to investigate associations among categorical variables (for example smoking status according to educational level or the smoking status of the partner). Exact $p<0.05$ were considered statistically significant. Data analysis was performed with SPSS software, version 18.0 (Chicago, IL).

\section{RESULTS}

Mean age was $31.2 \pm 5.5$ years (range: $15-49$ ), participants were assessed at $36 \pm 5$ weeks of pregnancy (median: 37 weeks, range: 6-41) and had $1.7 \pm 0.8$ number of pregnancies. Eleven women were assessed between the 11th and 20th week of pregnancy, and 6 had a gestational age of $\leq 10$ weeks. Demographic data and co-morbidities are presented in Table 1 .

Table 1. Sociodemographic data and co-morbidities of participants in the HELENA study in relation to their smoking status in pregnancy

\begin{tabular}{|c|c|c|c|c|}
\hline Characteristics & $\begin{array}{l}\text { Total number } \\
\qquad \begin{array}{c}(\mathrm{N}=1700) \\
n(\%)\end{array}\end{array}$ & $\begin{array}{c}\text { Non-smokers } \\
\left(\begin{array}{c}\mathrm{N}=996 ; 58.6 \%) \\
n(\%)\end{array}\right.\end{array}$ & $\begin{array}{c}\text { Smokers } \\
(\mathrm{N}=704 ; 41.4 \%) \\
n(\%)\end{array}$ & $p^{a}$ \\
\hline Age (years), Mean \pm SD & $31.2 \pm 5.5$ & $31.3 \pm 5.3$ & $31.1 \pm 5.7$ & 0.68 \\
\hline Pre-existing DM & $14(0.8)$ & $8(0.8)$ & $6(0.9)$ & \\
\hline DM of pregnancy & $90(5.3)$ & $53(5.3)$ & $37(5.3)$ & \\
\hline Pre-existing (chronic) $\mathrm{AH}$ & $6(0.4)$ & $2(0.2)$ & $4(0.6)$ & \\
\hline Gestational AH/ Preeclampsia & $94(5.5)$ & $41(4.1)$ & $53(7.5)$ & \\
\hline Dyslipidaemia & $19(1.1)$ & $11(1.1)$ & $8(1.1)$ & \\
\hline \multicolumn{5}{|l|}{ Age group (years) } \\
\hline$\leq 20$ & $45(2.6)$ & $17(1.7)$ & $28(4.0)$ & \\
\hline $21-30$ & $702(41.3)$ & $411(41.2)$ & $291(41.3)$ & \\
\hline $31-40$ & 905 (53.2) & $539(54.1)$ & $366(52.0)$ & \\
\hline$\geq 41$ & $48(2.8)$ & $29(2.9)$ & $19(2.7)$ & \\
\hline Parity $(n=1700)$ & & & & 0.003 \\
\hline Primipara & $811(47.7)$ & $446(44.8)$ & $365(51.8)$ & \\
\hline Multipara & $889(52.3)$ & $550(55.2)$ & $339(48.2)$ & \\
\hline Partner's smoking status $(n=1513)^{*}$ & & & & $<0.001$ \\
\hline Smoker & $463(30.6)$ & $167(16.9)$ & $296(56.4)$ & \\
\hline Non-smoker & $1050(69.4)$ & $821(83.1)$ & $229(43.6)$ & \\
\hline \multicolumn{5}{|l|}{ Educational level $(n=704)^{* *}$} \\
\hline High & $180(25.6)$ & $\mathrm{n} / \mathrm{a}^{* * *}$ & $180(25.6)$ & \\
\hline Non-high & $524(74.4)$ & $n / a^{* * *}$ & $524(74.4)$ & \\
\hline
\end{tabular}

DM: diabetes mellitus. AH: arterial hypertension. a The $p$ values were calculated by chi-squared test ( $<<0.05$ regarded as statistically significant). *Data for partner's smoking status available for 1513 individuals. ${ }^{* *}$ Data for educational level available for 704 individuals. ${ }^{* *}$ Education status recorded only for smokers. SD: standard deviation. 
Of the 1700 participants, 704 (41.4\%) were smokers. Of these, 369 (52.4\%) quit smoking after becoming aware of their pregnancy whereas 335 $(47.6 \%)$ chose to remain active smokers during pregnancy. There were no significant age differences neither between smokers and non-smokers $(p=0.68)$ nor between active smokers and quitters $(p=0.11)$. The overall prevalence of smoking in pregnancy in our population was, therefore, 19.7\% (Figure 1). Age group analysis is presented in Table 1. None of the 369 women who quit smoking reported to have received specialized medical advice in an organized smoking cessation counseling structure.

Although there were no significant differences between the second, third and fourth age group, our data show that in younger women ( $\leq 20$ years), the prevalence of smoking was significantly higher both before and during pregnancy $(\mathrm{p}=0.038)$.

Furthermore, among active smokers during pregnancy, a significant reduction was demonstrated in smoking burden as expressed by consumed cigarettes/day. Overall, reduction in cigarette consumption was recorded in $91.3 \%$ of the cases. More specifically, of 335 active smokers, 29 (8.7\%) did not change their smoking habits, 49 (14.6\%) reduced the cigarettes/day by $<50 \%, 123(36.7 \%)$ by $51-80 \%$, and $134(40 \%)$ by $>81 \%$.

Of the 1700 women, $52.3 \%$ were multipara (maximum 7 pregnancies). The prevalence of smoking was significantly higher in primipara women than in multipara, $45 \%$ versus $38.1 \%$ $(p=0.003)$. However, data analysis suggests that multipara women were less likely to quit, since of the 365 primipara women who were smokers before

Figure 1. Prevalence of smoking and factors associated with smoking cessation during pregnancy (N=1700).

(A) The effect of the maternal educational level on maternal smoking status. (B) The effect of parity on maternal smoking status. (C) The effect of partner's smoking status on maternal smoking status. (D)

Prevalence of smoking in pregnancy

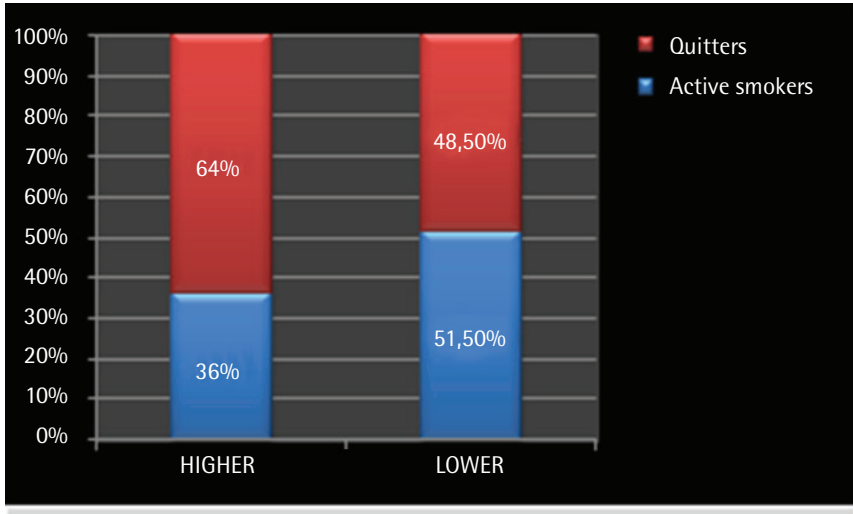

EDUCATIONAL LEVEL \& SMOKING STATUS IN PREGNANCY

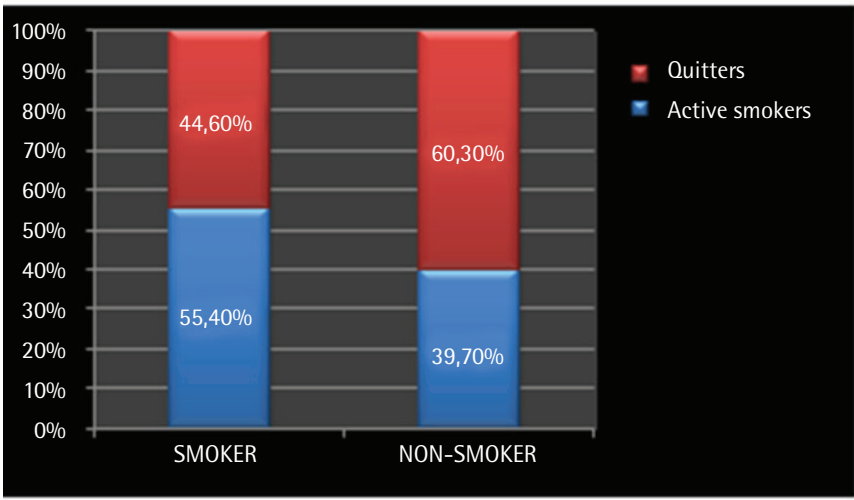

PARTNER'S SMOKING STATUS \& SMOKING STATUS IN PREGNANCY

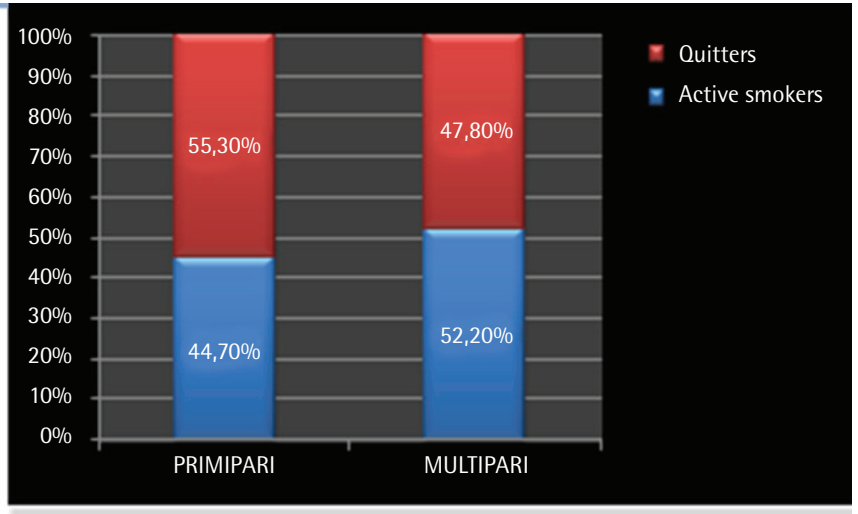

PARITY \& SMOKING STATUS IN PREGNANCY

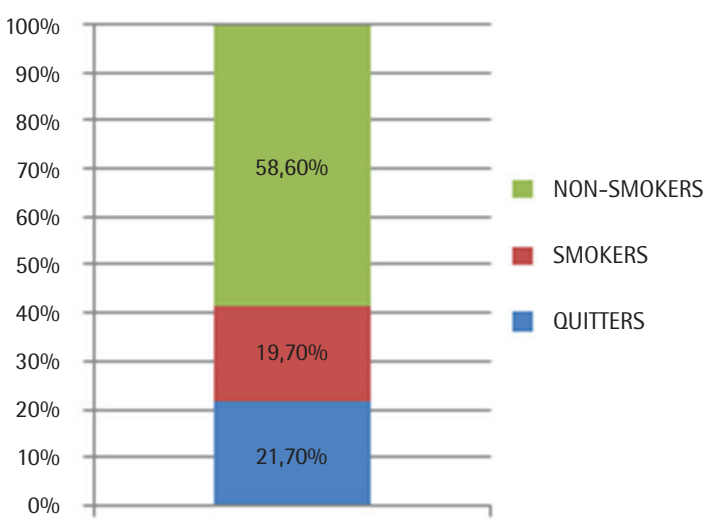

SMOKING IN PREGNANCY 
Table 2. Sociodemographic data and co-morbidities of participants in the HELENA study who smoked before pregnancy in relation to smoking cessation during pregnancy

\begin{tabular}{|c|c|c|c|c|}
\hline Characteristics & $\begin{array}{l}\text { Total number } \\
\qquad \begin{array}{c}\mathbf{N}=1700) \\
n(\%)\end{array}\end{array}$ & $\begin{array}{c}\text { Non-smokers } \\
\left(\begin{array}{c}\mathrm{N}=996 ; 58.6 \%) \\
n(\%)\end{array}\right.\end{array}$ & $\begin{array}{c}\text { Smokers } \\
(\mathrm{N}=704 ; 41.4 \%) \\
n(\%)\end{array}$ & $p^{a}$ \\
\hline Age (years), Mean $\pm S D$ & $31.1 \pm 5.7$ & $31.4 \pm 5.2$ & $30.7 \pm 6.2$ & 0.11 \\
\hline Pre-existing DM & $6(0.9)$ & $4(1.1)$ & $2(0.6)$ & \\
\hline DM of pregnancy & $37(5.3)$ & $16(4.3)$ & $21(6.3)$ & \\
\hline Pre-existing (chronic) AH & $4(0.6)$ & $1(0.27)$ & $3(0.9)$ & \\
\hline Gestational AH/ preeclampsia & $53(7.5)$ & $22(6.0)$ & $31(9.3)$ & \\
\hline Dyslipidaemia & $8(1.1)$ & $4(1.1)$ & $4(1.2)$ & \\
\hline \multicolumn{5}{|l|}{ Age group (years) } \\
\hline$\leq 20$ & $28(4.0)$ & $9(2.4)$ & 19 (5.67) & \\
\hline $21-30$ & $291(41.3)$ & $155(42)$ & $136(40.6)$ & \\
\hline $31-40$ & $366(52.0)$ & $196(53.1)$ & $170(50.1)$ & \\
\hline$\geq 41$ & $19(2.7)$ & $9(2.4)$ & $10(3.0)$ & \\
\hline Parity $(n=704)$ & & & & 0.032 \\
\hline Primipara & $365(51.8)$ & $207(56.1)$ & $158(47.2)$ & \\
\hline Multipara & $339(48.2)$ & $162(43.9)$ & $177(52.8)$ & \\
\hline Partner's smoking status $(n=525)^{*}$ & & & & 0.047 \\
\hline Smoker & $296(56.4)$ & $132(48.9)$ & $164(64.3)$ & \\
\hline Non-smoker & $229(43.6)$ & $138(51.1)$ & $91(35.7)$ & \\
\hline Educational level $(n=704)^{* *}$ & & & & 0.044 \\
\hline High & $180(25.6)$ & $115(31.2)$ & 65 (19.4) & \\
\hline Non-high & $524(74.4)$ & $254(68.8)$ & $270(80.6)$ & \\
\hline
\end{tabular}

DM: diabetes mellitus. AH: arterial hypertension. a The $p$ values were calculated by chi-squared test ( $p<0.05$ regarded as statistically significant). ${ }^{*}$ Data for partner's smoking status available for 525 individuals. **Data for educational level available for 704 individuals. SD: standard deviation.

pregnancy $56.7 \%$ quit, whereas of the 339 multipara women who smoked $47.8 \%$ quit $(\mathrm{p}=0.032)$.

In addition, it was demonstrated that the prevalence of smoking was higher among women whose partners were also smokers (64\% vs $21.8 \%$ in women whose partners did not smoke, correlation coefficient $=0.38, \mathrm{p}<0.001)$. Moreover, pregnant women who were smokers had a higher chance to quit smoking during pregnancy if the partner was a non-smoker ( $60.3 \%$ vs $44.6 \%$ when the partner was also a smoker, $\mathrm{p}=0.047)$.

Finally, in the present study, high educational level was associated with quitting smoking in pregnancy, since $64 \%$ of smokers who had higher education quit smoking compared to $48.5 \%$ of those who received $\leq 12$ years of school education $(\mathrm{p}=0.044)$.

Data regarding parity, partner's smoking status and educational level are presented in Table 2 and Figure 1.

\section{DISCUSSION}

This study aimed to determine the prevalence and predisposing factors of smoking among pregnant women. Participants had a mean age of 31.2 years, consistent with previously reported maternal age patterns in Greece ${ }^{31}$. Our data revealed a high prevalence of $19.7 \%$ of women who continued smoking despite the fact that they were pregnant, which remains unchanged in the last years ${ }^{27,28}$. On the other hand, $52.4 \%$ of smokers quit after becoming aware of the pregnancy. Another finding was that women who remained active smokers during pregnancy significantly reduced the number of cigarettes consumed daily.

These findings are consistent with previous 
research among pregnant women in Greece. A prospective mother-child cohort $(n=1291$, mean age: 29 years), that assessed women at week 12 of gestation ${ }^{27}$ and a more recent cross-sectional survey $(n=300$, mean age: 33.76 years), assessing women in the first, second and third trimesters of pregnancy ${ }^{28}$, revealed a prevalence of smoking during pregnancy of $17 \%$ and $26.3 \%$, respectively.

In the current study, we recruited women living in a large city, in contrast to a previous study where $23 \%$ of the participants originated from rural areas ${ }^{27}$. Differences in smoking prevalence (e.g. $17 \%$ vs $19.7 \%$ ) may partly be explained by this difference in study design, as living in rural areas is associated with lower smoking rates, that do not change during pregnancy ${ }^{27,32}$.

In contrast to our findings, data from several Western European countries, Australia and the USA demonstrate significantly lower prevalence of smoking during pregnancy and a steady decrease in maternal smoking rates in the last years ${ }^{18,19,22-24}$. Nevertheless, smoking in pregnancy still remains a major public health issue, with a significant heterogeneity among different geographical $\operatorname{areas}^{20-23,25}$. In a recent systematic review and metaanalysis, the global prevalence of smoking during pregnancy was estimated to be $1.7 \%$, with the highest prevalence recorded in the European Region (8.1\%). Greece is included in the subgroup of countries with a prevalence of $15.1-20.0 \%^{33,34}$. Additionally, in another study from Germany, more than half of all smokers did not quit smoking completely during pregnancy ${ }^{35}$.

A particularly worrying finding of the present study was the high prevalence of smoking demonstrated among younger pregnant women. In addition, younger women were less likely to discontinue smoking during pregnancy $(32.1 \%$ vs $52.4 \%$ in the overall study population). These results were in line with recent data indicating that smoking rates remain high among younger pregnant women and teenagers while the prevalence of maternal smoking decreases with age $\mathrm{a}^{22-24,36}$. These findings may be attributed to the advanced marketing methods used by the tobacco industry for targeting this population, and also to the psychological, biological and socioeconomic changes occurring at adolescence leading young pregnant women in adopting a high-risk life-style.

In the present work, similar to other studies, we also found that the prevalence of smoking was significantly higher in women whose partners were also smokers ${ }^{26,37-39}$. Moreover, the presence of a partner who does not smoke or quits smoking during pregnancy increased the probability of the pregnant woman quitting smoking. Furthermore, in agreement with previous research, our data suggest that primipara women and women with a higher educational level are more likely to quit smoking during pregnancy $22,27,28,30,33,36,40,41$.

These findings suggest that maternity units should develop specialized smoking cessation counseling structures in order to educate pregnant women, their partners and close relatives on the risks of both active and passive smoking for the fetal, infant and mother's health. Secondly, the role of smoking cessation clinics should be improved and offered to pregnant women after referral from the counseling services. Thirdly, women of reproductive age, especially teenagers and young adults, should be educated about the potential adverse effects of tobacco by campaign programs, using mass media, social media and online courses. Moreover, a strict implementation of the existing laws, prohibiting smoking in most public places should be adopted. This strategy was proved to be effective in establishing smoke-free environments in public and work places and in reducing maternal smoking in pregnancy ${ }^{42}$. Finally, restricting exposure to tobacco industry targeting, such as banning tobacco advertisement should be introduced.

\section{Strengths and limitations}

The present study has the following strengths. First, to our knowledge, the current study is the largest of its kind in Greece, and has sufficient power to draw conclusions about the extent of the problem. Moreover, it provides useful up-to-date epidemiological data that enrich international literature, indicates that the strategies pursued so far were not effective and highlights the necessity for improved public health policies for tackling this problem.

However, this study also has several limitations. First, despite the fact that $96.2 \%$ of the recruited women had a gestational age $\geq 28$ weeks, a group of 64 women at $\leq 27$ weeks of pregnancy was also 
included in data analysis. Although this group is small it could influence the proportion of smokers and quitters of the study population. Estimates such as interruption or declining of smoking consumption during pregnancy, are highly dependent on the gestational age of recruitment, which differs largely among the included women in the present study. Second, due to the fact that miscarriage before the 20th week of gestation is a common adverse outcome due to smoking, a number of smokers might have been missed and the actual proportion of smokers in this study might have been affected, since, as we already mentioned, most subjects were recruited after the 28 th week of pregnancy. Third, data regarding smoking are based on self-reporting information and therefore smoking status during pregnancy may be underreported. Previous studies have also revealed a trend towards underreporting smoker status. Fourth, partner's smoking status may, similarly, be underreported. In addition, this information was not directly recorded from the partner, but was provided by the pregnant women. Moreover, the subgroup of non-smoker partners is heterogeneous, consisting of those who quit smoking and those being non-smokers before pregnancy. Fifth, some important parameters, such as education level of non-smoker women, important risk factors that affect the maternal smoking status, such as mental disorders and level of nicotine addiction, partner's data (e.g. age, education) and information about passive smoking were not recorded. These data could have provided a more accurate estimate of the characteristics of maternal smoking in pregnancy. Furthermore, data regarding the use of e-cigarettes and other electronic nicotine delivery systems were not recorded. However, e-cigarette vapor or aerosol may contain several harmful substances and, in addition, chemical compounds vary between brands. Therefore, most probably, these products are not safe to use during pregnancy. Finally, the characteristics of our study population may not fully correspond to those of the general population with regard to the income and educational level. Moreover, in our study we included women who lived in the city of Athens, however, women living in rural areas may manifest different behavior regarding their smoking habits in pregnancy. A study recruiting women from different parts of the country, followed up in multiple maternity centers would probably be more representative.

\section{CONCLUSIONS}

We demonstrated that the prevalence of smoking during pregnancy still remains at unacceptably high levels. Important factors associated with cessation of smoking during pregnancy were the educational level, parity and smoking status of the pregnant woman's partner. Public health authorities should enhance efforts to reduce maternal smoking through educating pregnant women, their partners and relatives as well as through sustained and diverse anti-smoking and tobacco-control activities.

\section{REFERENCES}

1. World Health Organization. World Health Report 2003: Shaping the Future. Geneva, Switzerland: World Health Organization; 2003. https://www.who.int/whr/2003/en/ whr03_en.pdf?ua=1. Accessed 19 November 2020.

2. Eurostat. Tobacco consumption statistics: Statistics Explained 2017. http://ec.europa.eu/eurostat/statisticsexplained/index.php/Tobacco_consumption_statistics. Accessed December 12, 2017.

3. Leonardi-Bee J, Smyth A, Britton J, Coleman T. Environmental tobacco smoke and fetal health: systematic review and meta-analysis. Arch Dis Child Fetal Neonatal Ed. 2008;93(5):F351-F361. doi:10.1136/adc.2007.133553

4. US Department of Health and Human Services. How tobacco smoke causes disease: a report of the Surgeon General. Atlanta, GA: Centers for Disease Control and Prevention; 2010. https://www.ncbi.nlm.nih.gov/books/ NBK53017/. Accessed February 11, 2018.

5. Shah NR, Bracken MB. A systematic review and metaanalysis of prospective studies on the association between maternal cigarette smoking and preterm delivery. Am J Obstet Gynecol. 2000;182(2):465-472. doi:10.1016/s0002-9378(00)70240-7

6. Miyake Y, Tanaka K, Arakawa M. Active and passive maternal smoking during pregnancy and birth outcomes: the Kyushu Okinawa maternal and child health study. BMC Pregnancy Childbirth. 2013;13:157. doi:10.1186/1471-2393-13-157

7. Flenady V, Koopmans L, Middleton P, et al. Major risk factors for stillbirth in high-income countries: a systematic review and meta-analysis. Lancet. 2011;377(9774):13311340. doi:10.1016/S0140-6736(10)62233-7

8. Fleming P, Blair PS. Sudden Infant Death Syndrome and parental smoking. Early Hum Dev. 2007;83(11):721-725. doi:10.1016/j.earlhumdev.2007.07.011

9. Wisborg K, Kesmodel U, Henriksen TB, Olsen SF, Secher 
NJ. A prospective study of smoking during pregnancy and SIDS. Arch Dis Child. 2000;83(3):203-206. doi:10.1136/adc.83.3.203

10. Pallotto EK, Kilbride HW. Perinatal outcome and later implications of intrauterine growth restriction. Clin Obstet Gynecol. 2006;49(2):257-269. doi:10.1097/00003081-200606000-00008

11. Hackshaw A, Rodeck C, Boniface S. Maternal smoking in pregnancy and birth defects: a systematic review based on 173687 malformed cases and 11.7 million controls. Hum Reprod Update. 2011;17(5):589-604. doi:10.1093/humupd/dmr022

12. Wu P. Maternal smoking during pregnancy and its effect on childhood asthma: understanding the puzzle. Am J Respir Crit Care Med. 2012;186(10):941-942. doi:10.1164/rccm.201209-1618ED

13. Wehby GL, Prater K, McCarthy AM, Castilla EE, Murray JC. The Impact of Maternal Smoking during Pregnancy on Early Child Neurodevelopment. J Hum Cap. 2011;5(2):207-254. doi:10.1086/660885

14. Oken E, Levitan EB, Gillman MW. Maternal smoking during pregnancy and child overweight: systematic review and meta-analysis. Int J Obesity. 2008;32(2):201-210. doi:10.1038/sj.ijo.0803760

15. Nilsson PM, Hofvendahl S, Hofvendahl E, Brandt L, Ekbom A. Smoking in pregnancy in relation to gender and adult mortality risk in offspring: the Helsingborg Birth Cohort Study. Scand J Public Health. 2006;34(6):660664. doi:10.1080/14034940600607509

16. Fagerstrom K. The epidemiology of smoking: health consequences and benefits of cessation. Drugs. 2002;62(Suppl 2):1-9. doi:10.2165/00003495-200262002-00001

17. Nordentoft M, Lou HC, Hansen D, et al. Intrauterine growth retardation and premature delivery: the influence of maternal smoking and psychosocial factors. Am J Public Health. 1996;86(3):347-354. doi:10.2105/ajph.86.3.347

18. Centers for Disease Control and Prevention. Tobacco Use and Pregnancy. https://www.cdc.gov/reproductivehealth/ maternalinfanthealth/tobaccousepregnancy/index.htm. Updated July 15, 2020. Accessed January 20, 2018.

19. Health and Social Care Information Centre (HSCIC). Statistics on Women's Smoking Status at Time of Delivery: England - Quarter 4, 2015-16. https://digital.nhs.uk/ data-and-information/publications/statistical/statisticson-women-s-smoking-status-at-time-of-deliveryengland/statistics-on-women-s-smoking-status-at-timeof-delivery-england-quarter-4-2015-16\#: :text=In\%20 England\%2C\%201\%20April\%202015per\%20cent $\% 20$ in $\% 202006 \% 2 F 07$. Published June 16, 2016. Accessed January 12, 2018.

20. Li Z, Zeki R, Hilder L, Sullivan E. Australia's mothers and babies 2010. Canberra, Australia: Australian Institute of Health and Welfare. https://www.aihw.gov.au/getmedia/ a5e20cf4-e032-4452-bf07-eb51bb124470/14513.pdf. aspx?inline=true. Accessed January 12, 2018.
21. Australian Institute of Health and Welfare. Mothers and Babies. Canberra, Australia: Australian Institute of Health and Welfare; 2014. https://www.aihw.gov.au/reportsstatistics/population-groups/mothers-babies/overview. Accessed March 20, 2018.

22. Schultze A, Kurz H, Stümpflen I, Hafner E. Smoking prevalence among pregnant women from 2007 to 2012 at a tertiary-care hospital. Eur J Pediatr. 2016;175(6):833840. doi:10.1007/s00431-016-2710-1

23. Reitan T, Callinan S. Changes in Smoking Rates Among Pregnant Women and the General Female Population in Australia, Finland, Norway, and Sweden. Nicotine Tob Res. 2017;19(3):282-289. doi:10.1093/ntr/ntw188

24. Ekblad M, Gissler M, Korkeila J, Lehtonen L. Trends and risk groups for smoking during pregnancy in Finland and other Nordic countries. Eur J Public Health. 2014;24(4):544-551. doi:10.1093/eurpub/ckt128

25. Blondel B, Coulm B, Bonnet C, Goffinet F, Le Ray C; National Coordination Group of the National Perinatal Surveys. Trends in perinatal health in metropolitan France from 1995 to 2016: Results from the French National Perinatal Surveys. J Gynecol Obstet Hum Reprod. 2017;46(10):701-713. doi:10.1016/j.jogoh.2017.09.002

26. Eurostat. Births and Fertility: Over 5 million births in EU in 2017, Women in EU have first child on average at 29. In: News Release, 44/2019 - 12 March 2019. https://ec.europa.eu/eurostat/documents/portlet_file_ entry/2995521/3-12032019-AP-EN.pdf/412879ef3993-44f5-8276-38b482c766d8. Accessed May 31, 2020.

27. Vardavas CI, Patelarou E, Chatzi L, et al. Factors associated with active smoking, quitting, and secondhand smoke exposure among pregnant women in Greece. J Epidemiol. 2010;20(5):355-362. doi:10.2188/jea.je20090156

28. Vivilaki VG, Diamanti A, Tzeli M, et al. Exposure to active and passive smoking among Greek pregnant women. Tob Induc Dis. 2016;14:12. doi:10.1186/s12971-016-0077-8

29. Kharkova OA, Krettek A, Grjibovski AM, Nieboer E, Odland JØ. Prevalence of smoking before and during pregnancy and changes in this habit during pregnancy in Northwest Russia: a Murmansk county birth registry study. Reprod Health. 2016;13:18. doi:10.1186/s12978-016-0144-x

30. Tong VT, Jones JR, Dietz PM, D'Angelo D, Bombard JM. Trends in smoking before, during, and after pregnancy Pregnancy Risk Assessment Monitoring System (PRAMS), United States, 31 sites, 2000-2005. MMWR Surveill Summ. 2009;58(4):1-29. PMID:19478726.

31. Mousiolis A, Baroutis G, Papantoniou N, Costalos C, Antsaklis A. Maternal age demographic trends in Greece from 1980 to 2008. J Reprod Med. 2013;58(5-6):246255. PMID:23763011.

32. Gikas A, Merkouris P, Skliros E, Sotiropoulos A. Urban-rural differences in smoking prevalence in Greece. Eur J Public Health. 2007;17(4):402. doi:10.1093/eurpub/ckm055

33. Lange S, Probst C, Rehm J, Popova S. National, regional, and global prevalence of smoking during pregnancy in 
the general population: a systematic review and metaanalysis. Lancet Glob Health. 2018;6(7):e769-e776. doi:10.1016/S2214-109X(18)30223-7

34. Diamanti A, Raftopoulos V, Lykeridou K, Katsaounou P. Smoking and Pregnancy: Where are we now? An Update of the Situation in Greece. Int J Caring Sci. 2019;12(1):7991. http://internationaljournalofcaringsciences.org/ docs/10_raftopoulos_12_1.pdf. Accessed November 19, 2020 .

35. Schneider S, Huy C, Schütz J, Diehl K. Smoking cessation during pregnancy: a systematic literature review. Drug Alcohol Rev. 2010;29(1):81-90. doi:10.1111/j.1465-3362.2009.00098.x

36. Colman GJ, Joyce T. Trends in smoking before, during, and after pregnancy in ten states. Am J Prev Med. 2003;24(1):29-35. doi:10.1016/s0749-3797(02)00574-3

37. Lai MC, Chou FS, Yang YJ, Wang CC, Lee MC. Tobacco use and environmental smoke exposure among Taiwanese pregnant smokers and recent quitters: risk perception, attitude, and avoidance behavior. Int J Environ Res Public Health. 2013;10(9):4104-4116. doi:10.3390/ijerph10094104

38. Leonardi-Bee J, Britton J, Venn A. Second hand smoke and adverse fetal outcomes in non smoking pregnant women: a meta-analysis. Pediatrics. 2011;127(4):734741. doi:10.1542/peds.2010-3041

39. El-Mohandes AA, Kiely M, Blake SM, Gantz MG, El-Khorazaty MN. An intervention to reduce environmental tobacco smoke exposure improves pregnancy outcomes. Pediatrics. 2010;125(4):721-728. doi:10.1542/peds.2009-1809

40. Giglia RC, Binns CW, Alfonso HS. Which women stop smoking during pregnancy and the effect on breastfeeding duration. BMC Public Health. 2006;6:195. doi:10.1186/1471-2458-6-195

41. Anderka M, Romitti PA, Sun L, Druschel C, Carmichael S, Shaw G. National Birth Defects Prevention S: Patterns of tobacco exposure before and during pregnancy. Acta Obstet Gynecol Scand. 2010;89(4):505-514. doi:10.3109/00016341003692261

42. Franchini M, Caruso C, Perico A, et al. Assessment of foetal exposure to cigarette smoke after recent implementations of smoke-free policy in Italy. Acta Paediatr. 2008;97(5):546550. doi:10.1111/j.1651-2227.2008.00762.x
CONFLICTS OF INTEREST

The authors have completed and submitted the ICMJE Form for Disclosure of Potential Conflicts of Interest and none was reported.

\section{FUNDING}

There was no source of funding for this research.

\section{AUTHORS' CONTRIBUTIONS}

GS and SA participated in study design, data collection and analysis and interpretation and manuscript drafting. KT participated in manuscript drafting and literature revision. IA, OP and GV participated in data collection and in reviewing the manuscript. KA did the statistical analysis. VK had the conception for the study, reviewed the manuscript, supervised the study and approved the submitted manuscript. TM contributed in the organization and supervision of the study and in the revision and final approval of the manuscript submitted.

PROVENANCE AND PEER REVIEW

Not commissioned; externally peer reviewed. 